\title{
Corrigendum
}

\section{Corrigendum to "Fully Covered Metallic Stents for the Treatment of Benign Airway Stenosis"}

\author{
Caroline Dahlqvist $\mathbb{D}^{1},{ }^{1}$ Sebahat Ocak, ${ }^{1}$ Maximilien Gourdin, ${ }^{2}$ Anne Sophie Dincq $\mathbb{D}^{2}{ }^{2}$ \\ Laurie Putz $\left(\mathbb{D},{ }^{2}\right.$ and Jean-Paul d'Odémont ${ }^{1}$ \\ ${ }^{1}$ Division of Pulmonology, CHU UCL Namur (Godinne Site), Université catholique de Louvain (UcL), Yvoir, Namur, Belgium \\ ${ }^{2}$ Department of Anaesthesiology, CHU UCL Namur (Godinne Site), Université catholique de Louvain (UcL), \\ Yvoir, Namur, Belgium
}

Correspondence should be addressed to Caroline Dahlqvist; caroline.dahlqvist@uclouvain.be

Received 5 April 2018; Accepted 10 April 2018; Published 22 May 2018

Copyright (c) 2018 Caroline Dahlqvist et al. This is an open access article distributed under the Creative Commons Attribution License, which permits unrestricted use, distribution, and reproduction in any medium, provided the original work is properly cited.

In the article titled "Fully Covered Metallic Stents for the Treatment of Benign Airway Stenosis" [1], the location of the company "Micro-Tech ${ }^{\circledR}$ FC-SEMS" was incorrectly stated in the Abstract as "Micro-Tech ${ }^{\circledR}$ FC-SEMS (Nanjing Co., Republic of Korea)" and in the Introduction and Methods as "Micro-TechFC-SEMS (Nanjing Co., Korea)." It should be corrected to "Micro-Tech ${ }^{\circledR}$ FC-SEMS (Nanjing Co., China).

\section{References}

[1] C. Dahlqvist, S. Ocak, M. Gourdin, A. S. Dincq, L. Putz, and J.-P. d'Odémont, "Fully covered metallic stents for the treatment of Benign airway stenosis," Canadian Respiratory Journal, vol. 2016, Article ID 8085216, 7 pages, 2016. 


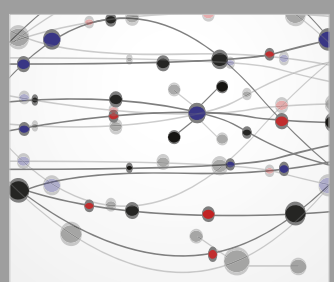

The Scientific World Journal
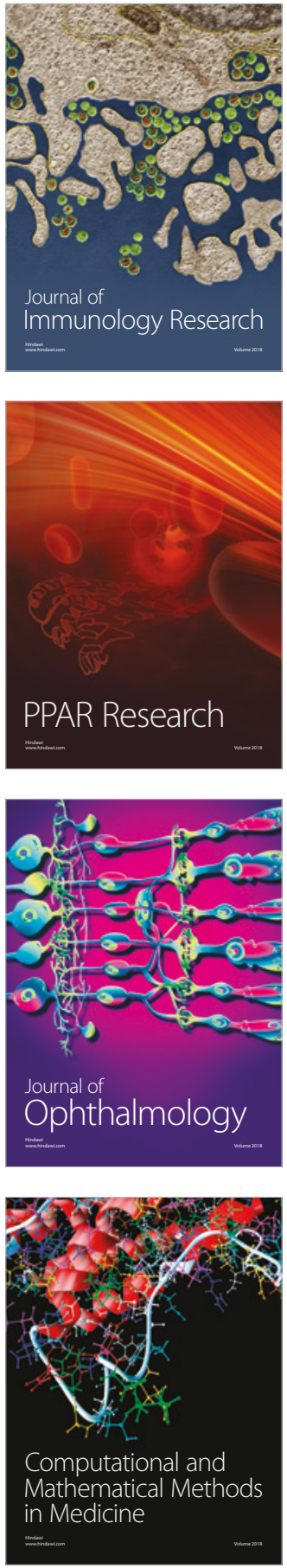

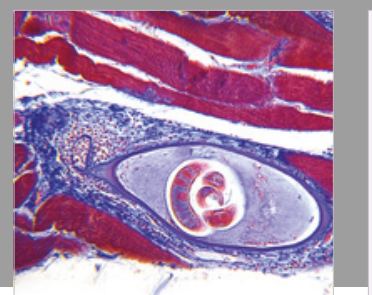

Gastroenterology Research and Practice

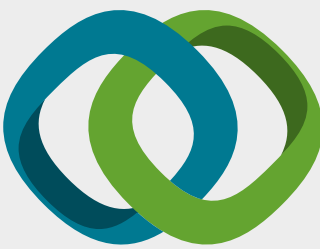

\section{Hindawi}

Submit your manuscripts at

www.hindawi.com
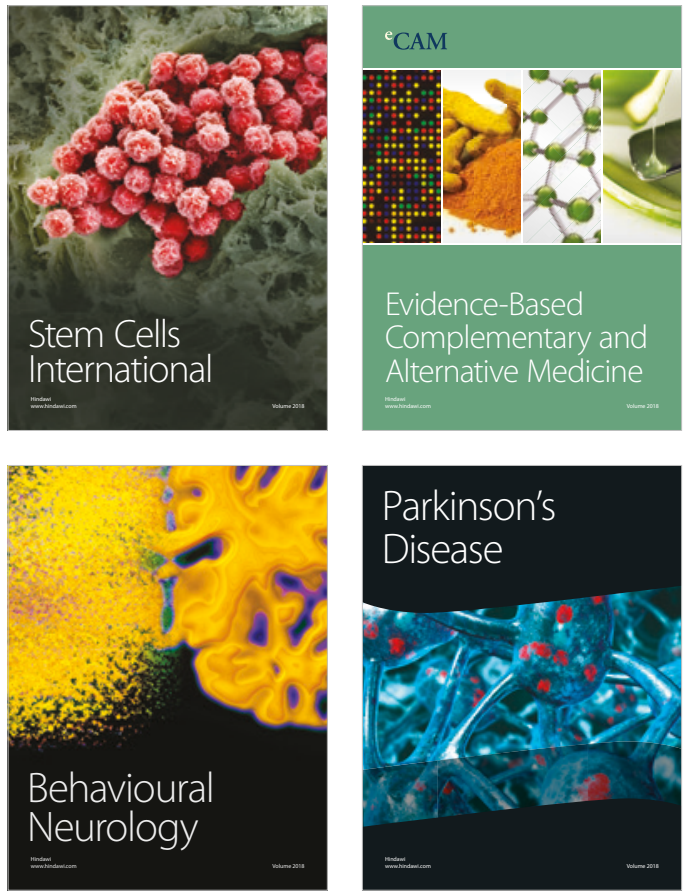

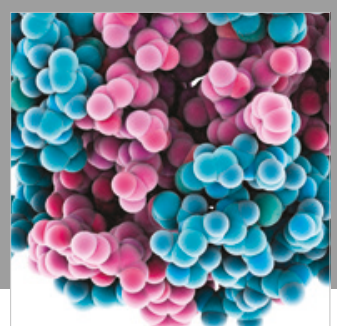

ournal of

Diabetes Research

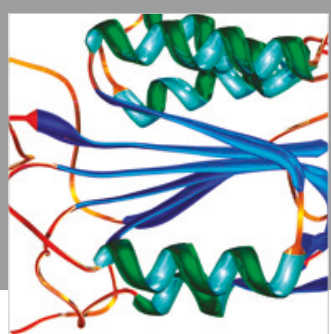

Disease Markers
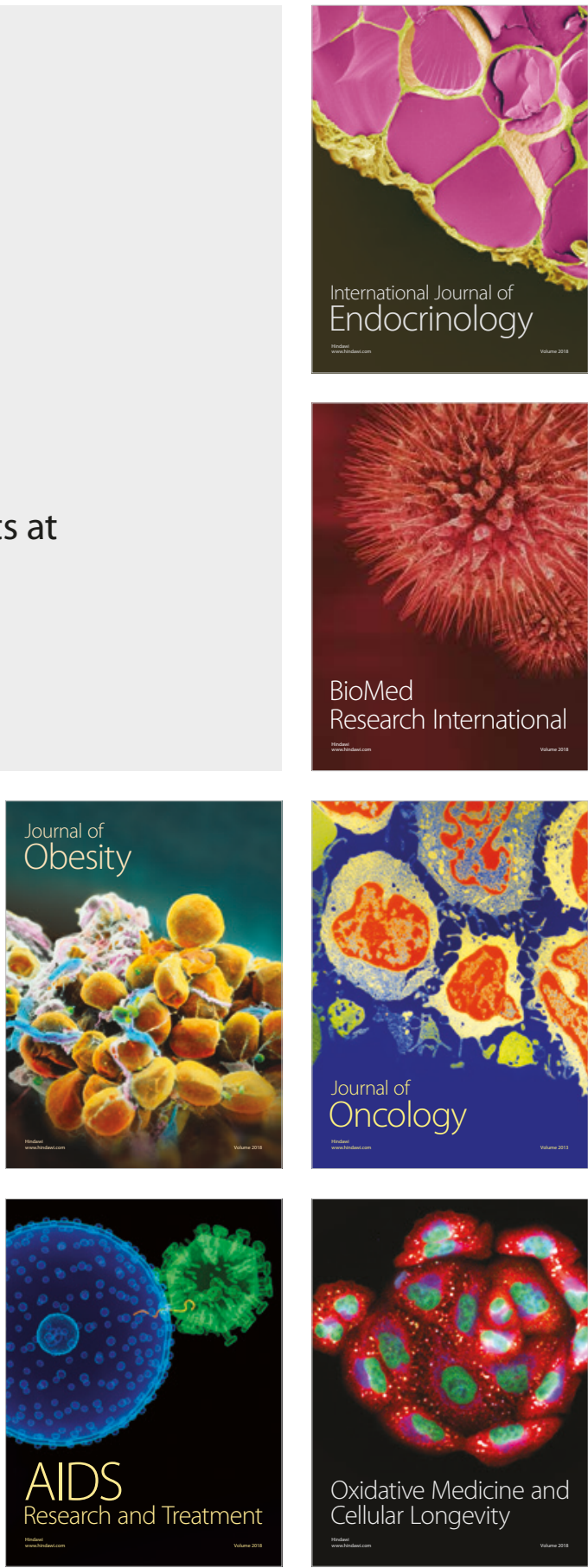